\title{
BMJ Open Effect of a multifaceted intervention on the utilisation of primary health for maternal and child health care in rural Nigeria: a quasi-experimental study
}

Friday Okonofua, ${ }^{1,2}$ Lorretta Favour Ntoimo (D) ,, ${ }^{1,3}$ Sanni Yaya, ${ }^{4,5}$ Brian Igboin, ${ }^{1}$ Ojuolape Solanke, ${ }^{6}$ Chioma Ekwo, ${ }^{1}$ Ermel Ameswue Kpogbe Johnson (1) , ${ }^{7}$ Issiaka Sombie, ${ }^{7}$ Wilson Imongan ${ }^{1}$

To cite: Okonofua F, Ntoimo LF, Yaya S, et al. Effect of a multifaceted intervention on the utilisation of primary health for maternal and child health care in rural Nigeria: a quasiexperimental study. BMJ Open 2022;12:e049499. doi:10.1136/ bmjopen-2021-049499

- Prepublication history and additional supplemental material for this paper are available online. To view these files, please visit the journal online (http://dx.doi.org/10.1136/ bmjopen-2021-049499).

Received 25 January 2021 Accepted 05 January 2022

Check for updates

(c) Author(s) (or their employer(s)) 2022. Re-use permitted under CC BY-NC. No commercial re-use. See rights and permissions. Published by BMJ.

For numbered affiliations see end of article.

Correspondence to

Dr Friday Okonofua;

feokonofua@yahoo.co.uk

\section{ABSTRACT}

Objective The objective of this study was to determine the effectiveness of a set of multifaceted interventions designed to increase the access of rural women to antenatal, intrapartum, postpartum and childhood immunisation services offered in primary healthcare facilities.

Design The study was a separate sample pretest-posttest quasi-experimental research.

Setting The research was conducted in 20 communities and primary health centres in Esan South East and Etsako East Local Government Areas in Edo State in southern Nigeria

Participants Randomly selected sample of ever married women aged $15-45$ years.

Interventions Seven community-led interventions implemented over 27 months, consisting of a community health fund, engagement of transport owners on emergency transport of pregnant women to primary health centres with the use of rapid short message service (SMS), drug revolving fund, community education, advocacy, retraining of health workers and provision of basic equipment.

Primary and secondary outcome measures The outcome measures included the number of women who used the primary health centres for skilled pregnancy care and immunisation of children aged 0-23 months.

Results After adjusting for clustering and confounding variables, the odds of using the project primary healthcare centres for the four outcomes were significantly higher at endline compared with baseline: antenatal care (OR $3.87, \mathrm{Cl} 2.84$ to $5.26 \mathrm{p}<0.001)$, delivery care $(\mathrm{OR} 3.88, \mathrm{Cl}$ 2.86 to 5.26 ), postnatal care (OR $3.66, \mathrm{Cl} 2.58$ to 5.18 ) and childhood immunisation (OR 2.87, $\mathrm{Cl} 1.90$ to 4.33). However, a few women still reported that the cost of services and gender-related issues were reasons for nonuse after the intervention.

Conclusion We conclude that community-led interventions that address the specific concerns of women related to the bottlenecks they experience in accessing care in primary health centres are effective in increasing demand for skilled pregnancy and childcare in rural Nigeria.
Strengths and limitations of this study

- This study engaged community-led interventions to address the low utilisation of primary healthcare in rural Nigeria.

- The interventions were multifaceted, implemented simultaneously and targeted various demand and supply barriers identified at baseline.

- The study design (separate sample pretest-posttest design) eliminated testing as a source of invalidity and used the same questionnaire at the baseline and end survey thereby eliminating the instrumentation effect.

- The study design controlled for clustering, while the personal characteristics of the respondents were adjusted in the estimation. No new interventions by the government or related agencies related to the promotion of PHC took place in the communities during the period of the project.

- Due to the composite nature of the project activities, it is difficult to identify anyone intervention activity as being more pre-eminent in leveraging the success of the intervention.

\section{INTRODUCTION}

Over the past years, there has been a global movement towards reducing high rates of maternal and under-5 mortality as essential prerequisites for socioeconomic development. It is for this reason that these milestones were listed for achievement in the Millennium Development Goals, and now the Sustainable Development Goals. ${ }^{12}$ More recently, at the international conference organised by the UNFPA to celebrate 25 years after the International Conference for Population and Development (ICPD), world leaders from several countries made commitments for attaining zero preventable maternal deaths globally by $2030 .^{3}$ It is evident that if this new vision is to be reached globally, countries such as Nigeria with high rates of 
neonatal and maternal mortality, would require specific attention. Nigeria's maternal mortality rate of $814 / 100$ 000 live births, with an estimated 58000 annual maternal deaths, and under-5 mortality of 117/1000 live births are currently among the world's highest. ${ }^{45}$ We conjecture that if an accelerated rate of decline in maternal and under-5 mortality is to be accomplished, the country would need to focus on specific interventions for its most vulnerable citizens.

Several lines of research have revealed that women in rural communities in Nigeria are at higher risk of maternal mortality as compared with those in urban areas. ${ }^{67}$ This is largely due to the limited access of rural women to skilled birth attendants because of the relative lack of functional health facilities in rural locations. ${ }^{8}$ In contrast, there is evidence that rural women use unskilled traditional birth attendants, increasing their risks of mortality when they experience severe obstetric complications. ${ }^{9}{ }^{10}$ While there have been policies and interventions that address maternal and child healthcare in Nigeria, only a few of such interventions have focused specifically on rural communities, where needs are more severe and the prevention of maternal and child mortality is more urgent.

The Nigerian health authorities have identified primary healthcare centres (PHCs) as entry points for women seeking skilled pregnancy (antenatal, intrapartum and postnatal) and child care. ${ }^{11-13}$ The PHCs are located in administrative wards and within less than $5 \mathrm{~km}$ of distance to residential areas. They are managed by 774 local government areas (LGAs) in the country. Each LGA has between 10-12 wards, with each ward consisting of about 5000 persons. This pattern of distribution means that the PHCs are available and accessible for use by widely dispersed populations, including women in rural populations. There are presently about 36000 primary health facilities in the country, with a large proportion located in rural communities. Under this arrangement, women living in rural wards are expected to seek skilled pregnancy care in the PHCs closest to them and can only be referred to higher levels of care (General and Specialist Hospitals) when they experience severe complications. Despite this arrangement, there is evidence that many pregnant women do not use existing PHCs for maternity care but rather use traditional or home-based methods. ${ }^{14-16}$

In assessing the use of PHCs for skilled pregnancy care, our team conducted initial formative research that showed that less than $47 \%$ of pregnant women in rural Edo used any of the available PHCs for care. ${ }^{16}$ We further ascertained through mixed qualitative research that these were due to perceptions relating to poor-quality services, high-cost of services, poor roads and transportation difficulty, gender and cultural issues and perceptions that PHCs may not be the appropriate places for women to receive antenatal and delivery care. ${ }^{10-19}$ To address these concerns, we worked with leaders in 20 communities in the area in collaboration with policymakers, sector planners and other stakeholders to design interventions to address the bottlenecks identified as preventing the use of skilled care by pregnant women in the communities. The interventions were solely led by members of the ward development committees (WDC) . The objective of this paper is to report the effectiveness of the interventions in increasing the access of women in the communities to antenatal, intrapartum, postpartum and childhood immunisation services offered in PHCs. We believe that the results have implications for demand generation for skilled pregnancy and childcare, and the reduction of maternal and under-5 mortality in rural communities.

\section{METHODS}

\section{Study setting}

The study was conducted in two rural LGAs (Esan SouthEast and Etsako East) in Edo State, Nigeria from December 2015 to November 2020. Nigeria is made up of 36 States and a Federal Capital Territory, Abuja. Each State consists of LGAs, and each LGA is further divided administratively into political/health wards, and a ward comprises several small communities or villages. Edo State is one of Nigeria's 36 states located in the South-South region. The State has an estimated population of 4.7 million in 2020 and 18 LGAs. ${ }^{20}$ The study was conducted in two of Edo State's LGAs identified above. Both LGAs are located in the riverine areas of the state, adjacent to River Niger with Estako East in the northern part of the Edo State part of the river, while Esan South East is in the southern part. The two LGAs have a total population of 455432 persons, with Esan South East accounting for 241492 and Etsako East LGA accounting for 213,940. ${ }^{20}$

Nigeria operates a three-tier healthcare system with primary healthcare as the entry into the health system, the secondary health facilities also called general hospitals and the tertiary/teaching hospitals at the apex. The secondary and tertiary hospitals are referral hospitals. The country has a functional referral system with the conditions for referral clearly specified in the protocols and manuals that guide service delivery at the lower levels of care. ${ }^{1321}$ The PHCs are controlled by the LGAs, whereas the Federal Government controls the tertiary/teaching hospitals. Presently, Nigeria has 40338 operational hospitals and clinics, and $85 \%$ are primary healthcare facilities and many are privately-owned health facilities, where routine, basic and comprehensive emergency obstetric care services are offered. ${ }^{22}$

Nigeria has one of the largest stocks of human resources for health in Africa with a doctor and nurse/midwife population ratio of 38.9 and 148 per 100000 population, respectively. These ratios are far above the sub-Saharan African average of 15 , and 72 per 100000 population for doctors and nurses, respectively. ${ }^{23} \mathrm{PHC}$ workers typically consist of one medical officer if available, one community health worker who must work with standing order, four nurse/midwives, three community health extension workers (CHEWs) who also must work with standing order, one pharmacy technician, six junior CHEWs 
who must work with standing order, one environmental officer, one medical records officer and one laboratory technician. Support staff includes two health attendants/ assistants, two security personnel and one general maintenance staff. ${ }^{13}$

The principal sources of maternity care in the two LGAs are PHCs. However, Esan South East LGA has one general hospital in Ubiaja (headquarters of the LGA) while Etsako East has one General Hospital in Agenebode (the LGA administrative headquarters) and another in nearby Fugar City. Several private hospitals also exist in both LGAs that offer maternal and child health services of various degrees of quality.

\section{Study design}

The study was a pretest-post-test, quasi-experimental design. The study was conducted in three phases: pretest (baseline), intervention and post-test (endline). A baseline mixed-method research comprising a household survey with ever-married women aged 15-45 years was conducted from 29 July to 16 August 2017. The intervention was implemented simultaneously from January 2018 to March 2020 (27 months). At the end of the intervention, an endline household survey was conducted between 24 June and 6 July 2020, using the same study instrument, to evaluate the effect of the intervention.

\section{Sampling technique and sample size}

The effect of the intervention was measured using a household survey with ever married women aged 15-45, at baseline and endline. At baseline, eight wards were randomly selected from the 20 wards in the two LGAs, and 20 communities (also regarded as clusters) were randomly selected from the eight wards. To maximise local efforts and for ease of management, the intervention was limited to two of the eight baseline wards. The two wards have 31 communities and four PHCs. The sample size at both baseline and endline was 1318. To adjust for non-response, $10 \%$ was added to derive a sample size of 1450 (725 per LGA). At baseline, twenty communities (also regarded as clusters) were randomly selected from eight wards in the two LGAs (10 communities per LGA), and a total of 1408 women were successfully interviewed from 3462 households in these 20 communities. The details of the sampling technique have been described elsewhere. ${ }^{16}$ After the intervention, an end household survey was conducted with a separate cluster sample of ever married women ages $15-45$ in 20 communities. A total of 1411 women were successfully interviewed from 3116 households in the 20 communities. The eligibility criteria were ever married, had a birth in the 2 years before the end survey and was not a respondent in the baseline survey.

\section{Intervention}

The aim of the intervention was to increase women's access to skilled pregnancy and child care. The baseline research identified the factors that limit women's access to skilled pregnancy care. Subsequently, the results were shared with community stakeholders, who then advised on appropriate interventions to address the identified bottlenecks. The implementation of the intervention activities was led by WDC whose members were selected by the traditional rulers and key decision-makers in the communities. One of the WDC members serves as the chairperson. The WDC is an initiative of the Federal Ministry of Health to oversee the activities of primary health centres in the political/health wards in Nigeria. ${ }^{24}{ }^{25}$ Seven intervention activities were implemented as described below following the TIDieR checklist. Anchored on the three-delay model, the interventions were designed to reduce the barriers to utilisation of skilled care provided in PHCs. Each intervention activity was monitored during the intervention using appropriate process indicators.

\section{Community health fund}

This was a local community fund-raising and contributory insurance named 'Igho Omoh' (meaning 'money to protect the child') and 'Ikpagie Omo' (meaning 'financial savings for the child') that enabled participating pregnant women to obtain treatment at PHCs without being deterred by an inability to pay. Pregnant women registered with payments of a total of 2000 (US\$5.26), which could be paid in instalments. A registration card was issued to the women which contained details such as name, address, contact details and those of her partner, the telephone numbers of the WDC chairman and the rapid SMS keyword and telephone number. A community-level fundraising activity took place bi-annually to support the scheme. Women who registered in this fund were entitled to free delivery care, which cost about $\$ 4500$ (US $\$ 11.84$ ) on average for normal delivery and to access the transportation and rapid SMS interventions. A total of 765 pregnant women registered in the fund during the intervention. The funds were paid into a bank account held by the WDCs, while monthly reporting of the proceeds of the account was made to all members and the traditional leaders.

\section{Memorandum of understanding with transport owners}

This was to address barriers due to lack of transportation. The WDC registered interested transport owners and committed them to make their transport services available to pregnant women in case of an emergency. The specified rates were paid from the community health fund by the WDC at the end of the service. This was widely advertised and used during the period by pregnant women in the communities.

\section{Rapid SMS called 'Text4Life'}

This is real-time two-way communication between a pregnant woman in distress, the WDC chairman and the PHC nurse, using a mobile phone. The woman triggers an alert system by sending a keyword to a phone number configured to a central server. The woman gets automated feedback from the server to wait. At the same 
time, a dual SMS with the woman's name and address is relayed to the WDC chairperson and the nurse, reporting an emergency. The WDC chairman calls one of the registered transport owners to pick up the woman, while the nurse prepares to receive her. Telephones were given to the WDC chairperson, the nurse in charge at the PHCs and to a few pregnant women who had no telephone. The women and their partners were taught how to use Text4Life during registration in the community health fund, and antenatal care visits.

\section{Drug revolving fund}

A drug revolving fund (DRF) was set up for each of the four project PHCs. The WDC members and the project PHC providers were trained by the Edo State Ministry of Health on the techniques of managing a DRF. This ensured the availability of essential drugs in the project PHCs at affordable prices. Initial funds were provided by one of the community leaders to start the funds. The returns were paid into the WDC project bank accounts, from which replenishments of stock-outs were made periodically.

\section{Community health talks}

Community sensitisation and health talks led by the WDC took place regularly in the project communities. The WDC members were taught by the project technical committee to implement the health talks, some of which took place on a house-to-house basis. We also produced and distributed informational materials to women and their families on the importance of using PHCs during the talks.

\section{Advocacy activities}

An advocacy team was set up to identify stakeholders in the communities and government. The aim was to sustain the project's results through community commitment and ownership and policymakers' active support. The team paid advocacy visits to the Deputy Governor, the Federal Ministry of Health, the Edo State Ministry of Health and to LGA Council chairmen. It was such advocated visits that resulted in the allocation of more nurses and midwives to the PHCs, the provision of support funds to the project from various leaders of the community, for example, for the construction of a residential quarter for doctors, the donation of two mobile ambulances and the donation of equipment and facilities to the project PHCs.

\section{Staffing, training and retraining and provision of basic equipment}

Nurses and midwives in the PHCs were given regular training on basic maternal and child care. This consisted of hands-on quarterly training on safe delivery using the WHO guidelines of PHC delivery, the demonstration of vaginal delivery, proper management of the third stage of labour and the resuscitation of the newborn. We also taught the parthographic management of labour and the points at which women with prolonged labour should be referred to secondary care facilities. Also, delivery kits were supplied to the PHCs ; mattresses, bedsheets and pillows were replaced in the PHCs, where these were either lacking or worn out; functional tricycles were provided by the LGA for transportation and referral of women, and personal protective equipment was supplied to the four PHCs at the time of out-break of the COVID-19 pandemic.

\section{Data collection}

The same pretested household survey questionnaire was administered face-to-face by trained field assistants using computer-assisted personal interviewing (CAPI) at baseline and after the intervention. The questionnaire consisted of five sections. Section 1 contained the respondents' sociodemographic characteristics; section 2 was on partners' and other family characteristics, section 3 contained questions on the respondents' reproductive history, section 4 was on antenatal, intrapartum and postnatal care experience for pregnancy and births in the preceding 2 years, and immunisation for children age 0-23 months. Section 5 contained questions on barriers to utilisation of PHCs for maternal and childcare.

\section{Patient and public involvement}

The WDC was involved in the intervention design and implementation.

\section{Variables and measures}

The outcome variables were the use of a PHC in the project wards for skilled antenatal care, delivery care, a postnatal check-up for mother and child and any of the recommended immunisation for the children age 0-23 months for the respondents' most recent birth 2 years before each survey. The use of a PHC in the project wards was coded 1 , whereas the use of other facilities was coded 0 for each of the four outcomes. The explanatory variable was the survey period indicated as baseline and endline. The baseline was the reference category.

Drawing from previous studies and theoretical perspectives on the utilisation of maternal and child health services, ${ }^{26-30}$ some individual and family-level factors were added to control the likely effect of any variation in the characteristics of the respondents at baseline and endline. The control variables included age recorded in single years, the highest level of education (no education, primary, secondary, higher), access to the media. A measure of access to the media (more, less and no exposure) was generated by aggregating the responses to the frequency of listening to the radio and watching television. Religion was categorised as Catholic, Other Christian, Islam, Traditionalist and others. Due to small numbers, Islam, Traditionalists and others were merged for the multivariable analysis. Other characteristics were work status categorised as working and not working; age at marriage in single years; marital status categorised as married, living together and formerly married (widowed, divorced and separated); type of union (monogamous and polygynous) and LGA. The respondents were also asked their most important reasons for using or not using 
a PHC for skilled care. Multiple response options such as the cost is too much, providers are not available and quality of care among others were provided.

\section{Analytical approach}

The data were extracted from the CAPI device into SPSS V.20, and Stata V.13 was used for analysis. The characteristics of all the respondents at baseline and endline and the prevalence of the outcome variables were described using frequency, percentage, mean and SD where appropriate. The difference in the outcomes between the two periods was presented as the difference between the percentage at baseline and the percentage at endline. An assessment of the significant difference in the characteristics of the respondents at the two periods was conducted with a t test for continuous variables, and a test of association for categorical variables using $\chi^{2}$ and Fisher's exact test, where the assumptions for $\chi^{2}$ was not met. All the frequencies in the distribution of the study population by the outcome variables do not total to 1408 (baseline) and 1411 (end line) due to non-response. To determine the effect of the intervention on the utilisation of PHCs for maternal and child care, binary logistic regression was conducted with the survey period as the explanatory variable adjusting for clustering at the community level, and individual and family characteristics of the respondents that may have influenced change between baseline and endline. The respondents' sociodemographic and family characteristics were adjusted in the logit model.

The result of the multiple responses to the most important reasons for the use and non-use of a PHC for delivery care was compared between baseline and end line. Each reason for use or non-use was generated as a dummy variable with yes as the positive response and no otherwise. A test of association was conducted using $\chi^{2}$ or Fisher's exact test where appropriate, for each reason and the survey period (baseline and endline). $\mathrm{P}$ values from these tests were reported with the frequency of the positive response to each reason and the corresponding percentage of the total number of respondents at endline who used or did not use the PHCs in the project communities, excluding non-response.

The level of statistical significance in all the statistical tests was set at $\leq 0.05$ (95\% CI and all $p$ values were two sided).

\section{RESULTS}

\section{Profile of the study population}

A total of 2819women participated in this study: 1408 at baseline and 1411 at endline. The characteristics of the study population at both the baseline and endline are presented in table 1 . The mean age of the women at baseline and endline was $30 \pm 7.0$ and $31.9 \pm 8.1$, respectively, and most of them attained primary and secondary education. Slightly above one quarter of all the respondents had no exposure to the media (radio and television). The majority were of other Christian affiliation, married in a

\begin{tabular}{|c|c|c|c|}
\hline Variable & $\begin{array}{l}\text { Baseline } \\
(n=1408)\end{array}$ & $\begin{array}{l}\text { Endline } \\
(n=1411)\end{array}$ & $P$ value \\
\hline \multicolumn{4}{|l|}{ Age $^{\star}$} \\
\hline Mean (SD) & $30.0(7.0)$ & $31.9(8.1)$ & $<0.001$ \\
\hline Education & & & $<0.01$ \\
\hline Higher & $83(5.9)$ & $62(4.4)$ & \\
\hline Secondary & $502(35.7)$ & $586(41.5)$ & \\
\hline Primary & $617(43.8)$ & $586(41.5)$ & \\
\hline No education & $206(14.6)$ & $177(12.5)$ & \\
\hline \multicolumn{3}{|c|}{ Exposure to the media } & $<0.01$ \\
\hline More exposure & $420(29.8)$ & 409 (29.0) & \\
\hline Less exposure & $666(47.3)$ & $600(42.5)$ & \\
\hline No exposure & 322 (22.9) & $402(28.5)$ & \\
\hline Religion & & & $<0.001$ \\
\hline Catholic & $369(26.2)$ & $379(26.9)$ & \\
\hline Other Christian & $884(62.8)$ & $971(68.8)$ & \\
\hline Islam & $145(10.3)$ & $42(3.0)$ & \\
\hline Traditionalist & $8(0.6)$ & $14(1.0)$ & \\
\hline Others & $1(0.1)$ & $5(0.4)$ & \\
\hline Work status & & & 0.08 \\
\hline Not working & $287(20.4)$ & $326(23.1)$ & \\
\hline Working & $1121(79.6)$ & $1085(76.9)$ & \\
\hline Marital status & & & $<0.001$ \\
\hline Married & $926(65.8)$ & $768(54.4)$ & \\
\hline Living together & $447(31.7)$ & 557 (39.5) & \\
\hline Formerly married & $35(2.5)$ & $86(6.1)$ & \\
\hline \multicolumn{4}{|l|}{ Age at marriage $\mathrm{e}^{\star}$} \\
\hline Mean (SD) & $21.0(4.0)$ & $20.4(4.9)$ & $<0.001$ \\
\hline Type of union & & & $<0.001$ \\
\hline Monogamous & 1109 (78.8) & $885(62.7)$ & \\
\hline Polygynous & 299 (21.2) & 526 (37.3) & \\
\hline
\end{tabular}

Number of

children*

\begin{tabular}{llll}
\hline Mean (SD) & $3.7(2.1)$ & $3.7(2.1)$ & 0.6923 \\
\hline \multicolumn{2}{l}{ Local government area } & & 0.778 \\
\hline Esan South East & $701(49.8)$ & $710(50.3)$ & \\
\hline Etsako East & $707(50.2)$ & $701(49.7)$ & \\
\hline
\end{tabular}

All $p$-values were derived from the $\chi^{2}$ test except for religion where Fisher's exact test was used because of cells with $<5$; and t-test for respondent's age, age at marriage, and the number of children, and child's age.

*Figures are mean values and SD in parenthesis. Figures for other variables are absolute numbers and percentages in parenthesis.

monogamous union, and had an average of 3.7 children. Most of the respondents at baseline and endline were working. The details on the type of work (not shown) show that most of the respondents were self-employed. 
Table 2 Distribution of the study population by the outcome variables (most recent birth)

\begin{tabular}{llll}
\hline Variable & $\begin{array}{l}\text { Baseline } \\
\text { N (\%) }\end{array}$ & $\begin{array}{l}\text { Endline } \\
\text { N (\%) }\end{array}$ & P value \\
\hline Antenatal care & & & \\
Yes & $972(74.0)$ & $1165(86.2)$ & $<0.001$ \\
No & $341(26.0)$ & $186(13.8)$ &
\end{tabular}

\section{Place of antenatal care}

$\begin{array}{llll}\text { Other } & 577(59.2) & 357(30.5) & <0.001 \\ \text { PHC in the project } & 397(40.8) & 813(69.5) & \\ \text { community } & & \end{array}$

\begin{tabular}{|c|c|c|c|}
\hline \multicolumn{4}{|l|}{ Place of delivery } \\
\hline Any facility & $988(75.2)$ & 1162 (85.5) & $<0.001$ \\
\hline TBA/home & $325(24.8)$ & 197 (14.5) & \\
\hline \multicolumn{4}{|l|}{ Place of delivery } \\
\hline Other & $896(68.2)$ & 557 (41.0) & $<0.001$ \\
\hline $\begin{array}{l}\mathrm{PHC} \text { in the project } \\
\text { community }\end{array}$ & $417(31.8)$ & $802(59.0)$ & \\
\hline
\end{tabular}

\begin{tabular}{lrcc} 
Postnatal care & & & \\
Yes & $1041(79.2)$ & $1256(92.5)$ & $<0.001$ \\
No & $273(20.8)$ & $102(7.5)$ & \\
\hline
\end{tabular}

Place of postnatal care

\begin{tabular}{|c|c|c|c|}
\hline Other & $614(58.8)$ & $385(30.5)$ & $<0.001$ \\
\hline $\begin{array}{l}\text { PHC in the project } \\
\text { community }\end{array}$ & $431(41.2)$ & 876 (69.5) & \\
\hline \multicolumn{4}{|l|}{ Immunisation } \\
\hline Other facilities & 504 (40.3) & 276 (21.4) & $<0.001$ \\
\hline $\begin{array}{l}\text { PHC in the project } \\
\text { community }\end{array}$ & 748 (59.7) & 1014 (78.6) & \\
\hline
\end{tabular}

PHC, primary healthcare centre; TBA, Traidtional Birth Attendant.

\section{Utilisation of PHCs at baseline and endline}

The distribution of the study population by the outcome variables is presented in table 2 . The percentage of women who used the project PHCs for antenatal care in their most recent birth increased from $40.8 \%$ at baseline to $69.5 \%$ at endline. The use of PHCs for delivery care increased from $31.8 \%$ at baseline to $59 \%$ at endline, while postnatal care increased from $41.2 \%$ at baseline to $69.5 \%$ at endline. The percentage of women who used PHCs for immunisation services for their children also increased from $59.7 \%$ at baseline to $78.6 \%$ at endline. The relationship between the outcome indicators and the periods was all statistically significant.

The odds of using a PHC in the project communities for each of the four outcomes at endline versus baseline are presented in table 3. Adjusting for clustering at the community level and the selected characteristics, the odds of using a PHC in the project communities for antenatal care were significantly higher at endline relative to baseline (OR 3.87, CI 2.84 to 5.26). The likelihood of using a PHC in the project communities for delivery increased at endline compared with baseline (OR 3.88, CI 2.86 to 5.26). The use of a PHC in the project sites for postnatal care was more likely at the endline than at baseline (OR 3.66, CI 2.58 to 5.18). Compared with the baseline, the odds of using a PHC in the project communities for immunisation increased at endline (OR 2.87, CI 1.90 to 4.33$)$.

Some of the control variables were significantly associated with the utilisation of the PHCs in the project sites for the four outcome indicators. The odds of using a PHC for antenatal, delivery and postnatal care significantly decreased with a woman's age. Relative to women who had attained higher education, the likelihood of using a PHC for antenatal, delivery and postnatal care was higher among women with lower levels of education or none. Compared with Catholics, respondents of Islamic, traditional and other religious affiliation were more likely to use a PHC in the project sites for antenatal care, delivery care and immunisation. Relative to the respondents who were married, those who were living together with a partner were less likely to use a PHC for child immunisation, and those who were formerly married were less likely to use a PHC for all four outcomes. Age at marriage predicted lower odds of using the project PHCs for immunisation. Respondents in a polygynous union were less likely to use a PHC for child immunisation. The higher the number of children the higher the likelihood of using the project PHCs for antenatal, delivery and postnatal care and immunisation. The use of the project sites was significantly lower in Etsako East LGA compared with Esan South East LGA.

\section{Reasons for use and non-use of a PHC for delivery at baseline and endline}

The most important reasons for using and not using a PHC for delivery care were compared between baseline and endline. The number of positive response to each reason for use or non-use and its percentage of the total number of respondents who used or did not use a PHC in the project communities are presented.

The reasons for use of a PHC in the project communities for delivery care are presented in table 4 . There was a decline at endline in the percentage of respondents who cited reasons for use as 'cost not too much', 'facility not too far from respondent's residence', 'the family wanted it', 'adequate security' and other reasons. In contrast, the percentage of respondents who cited facility always open, providers are available, good quality service and husband wanted it increased at endline. The reasons with the largest number of responses at baseline were 'facility is not too far', 'good quality service', 'cost not too much' and 'providers available', but at endline, 'good quality service', 'providers are available', 'facility always open' and 'cost not too much' were the most cited responses.

There was a statistically significant relationship between each reason at baseline and endline except for cost not too much and no charges. The non-response rate was $6 \%$ of the 417 respondents who used the PHCs in the project communities at baseline, whereas all the 802 respondents 
Table 3 Odds of using a PHC in the project communities for maternal and child healthcare

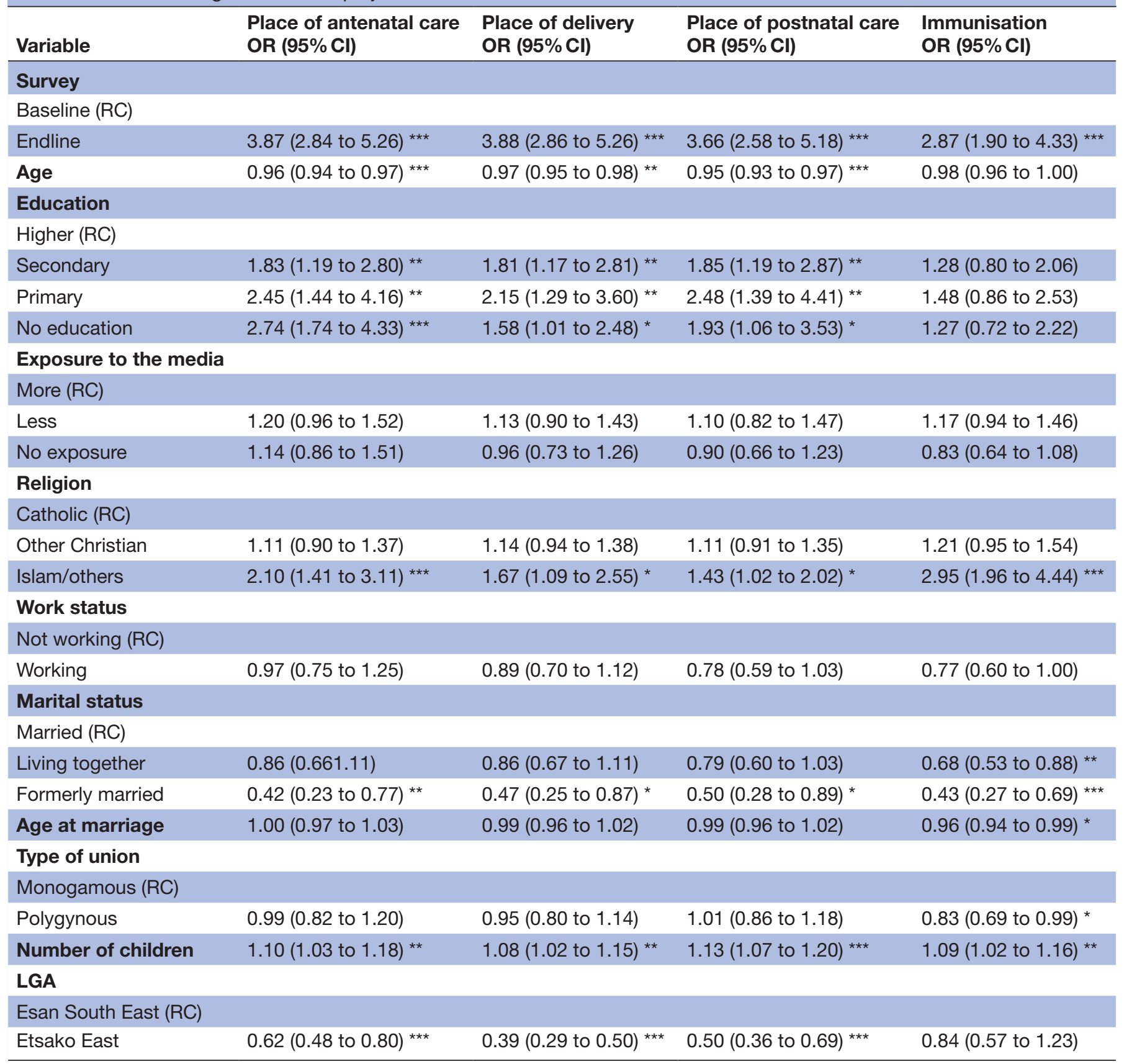

${ }^{* * *} \mathrm{P}<0.001 ;{ }^{* *} \mathrm{p}<0.01 ;{ }^{*} \mathrm{p}<0.05$.

Age, age at marriage and number of children have no reference category because they are continuous variables.

LGA, local government area; OR, Odds Ratio; PHC, primary healthcare centre; RC, reference category.

who used the PHCs in the project community responded to the question on reasons for use. See supplementary material for detailed result tables showing the positive and negative response to each reason.

The reasons for non-use of a PHC are presented in table 5. At endline, the percentage of responses for all the reasons decreased. The largest percentage point decline in the most important reason for non-use of a PHC in the project communities was in poor quality service, no provider in the facility, facility too far and facility not open. The relationship between the response at baseline and endline for each reason was statistically significant except for no security. The non-response rate was $38 \%-40 \%$ of the 896 respondents who did not use the PHCs in the project communities at baseline, and all the 557 respondents at endline responded. Details of the results are provided in the supplementary material.

\section{DISCUSSION}

The study was designed to determine the effectiveness of a multifaceted set of interventions in increasing the uptake 


\begin{tabular}{|c|c|c|c|c|}
\hline \multirow[b]{2}{*}{ S/N } & \multirow[b]{2}{*}{ Reason } & \multirow{2}{*}{$\begin{array}{l}\text { Baseline } \\
\mathrm{N}=417 \\
\mathrm{~N}(\%)\end{array}$} & \multirow{2}{*}{$\begin{array}{l}\text { Endline } \\
\mathrm{N}=802 \\
\mathbf{N}(\%)\end{array}$} & \multirow[b]{2}{*}{$P$ value } \\
\hline & & & & \\
\hline 1 & $\begin{array}{l}\text { Cost not too } \\
\text { much }\end{array}$ & $185(46.8)$ & $369(46.0)$ & 0.788 \\
\hline 2 & No charges & $4(1.0)$ & $17(2.1)$ & 0.241 \\
\hline 3 & $\begin{array}{l}\text { Facility always } \\
\text { open }\end{array}$ & $123(31.3)$ & 419 (52.2) & $<0.001$ \\
\hline 4 & $\begin{array}{l}\text { Providers are } \\
\text { available }\end{array}$ & $172(43.7)$ & $439(54.7)$ & 0.001 \\
\hline 5 & $\begin{array}{l}\text { Facility not far } \\
\text { from my home }\end{array}$ & 215 (54.6) & $287(35.8)$ & $<0.001$ \\
\hline 6 & $\begin{array}{l}\text { Good quality } \\
\text { service }\end{array}$ & $207(52.4)$ & $571(71.2)$ & $<0.001$ \\
\hline 7 & $\begin{array}{l}\text { Husband } \\
\text { wanted it }\end{array}$ & $94(23.9)$ & 245 (30.6) & $<0.016$ \\
\hline 8 & $\begin{array}{l}\text { Family wanted } \\
\text { it }\end{array}$ & $34(8.6)$ & $40(5.0)$ & 0.014 \\
\hline 9 & $\begin{array}{l}\text { Adequate } \\
\text { security }\end{array}$ & $26(6.6)$ & $8(1.0)$ & $<0.001$ \\
\hline 10 & Other (specify)* & $17(4.3)$ & $8(1.0)$ & $<0.001$ \\
\hline
\end{tabular}

${ }^{*}$ At endline, other includes available facility, no reason, drugs available and referred among others. Other at baseline includes baby's health/safety, no other facility among others. Non-response is excluded.

$\mathrm{PHC}$, primary healthcare centre.

of skilled maternal and child care in two rural LGAs in Edo State, Nigeria. The results showed high-level effectiveness of the interventions in improving the uptake of antenatal, delivery and postnatal care as well as childhood immunisation services by women in the LGAs. After controlling for clustering and possible confounding variables, the likelihood of use of PHCs for antenatal care among the rural women increased nearly fourfold, delivery care threefolds, postnatal care nearly fourfolds and childhood immunisation nearly threefolds as compared with the baseline. The effectiveness of the intervention is likely due to multiple factors, the most important being the design of the interventions to respond to the concerns raised by the women as responsible for their non-use of skilled pregnancy care. We particularly ensured that all concerns identified during the formative research were addressed in the various components of the intervention, leaving no areas for gaps and redundancies. The fact that the interventions were led by community WDC supported by community leaders also ensured the highlevel intensity of the implementation of the interventions and promoted rapid community acceptance and uptake.

Due to the composite nature of the project activities, it is difficult to identify anyone activity as being more pre-eminent in leveraging the success of the intervention. We understand that interventions are more likely
Table 5 Reasons for non-use of PHC for delivery care (most recent birth)

\begin{tabular}{|c|c|c|c|c|}
\hline & & $\begin{array}{l}\text { Baseline } \\
\mathrm{N}=896\end{array}$ & $\begin{array}{l}\text { End line } \\
\mathrm{N}=557\end{array}$ & \\
\hline $\mathbf{S} / \mathbf{N}$ & Reason & N (\%) & N (\%) & $P$ value \\
\hline 1 & Cost too much & 47 (13.2) & $6(1.1)$ & $<0.001$ \\
\hline 2 & Facility not open & 45 (12.7) & $10(1.8)$ & $<0.001$ \\
\hline 3 & $\begin{array}{l}\text { No provider in } \\
\text { the facility }\end{array}$ & $65(18.1)$ & $3(0.5)$ & $<0.001$ \\
\hline 4 & Facility too far & 61 (16.9) & $6(1.1)$ & $<0.001$ \\
\hline 5 & $\begin{array}{l}\text { No transport to } \\
\text { facility }\end{array}$ & $21(5.9)$ & $3(0.5)$ & $<0.001$ \\
\hline 6 & $\begin{array}{l}\text { Poor quality } \\
\text { service }\end{array}$ & 97 (27.4) & $4(0.7)$ & $<0.001$ \\
\hline 7 & $\begin{array}{l}\text { Husband did not } \\
\text { allow }\end{array}$ & $27(7.6)$ & $7(1.3)$ & $<0.001$ \\
\hline 8 & $\begin{array}{l}\text { Family did not } \\
\text { allow }\end{array}$ & $10(2.8)$ & $3(0.5)$ & 0.008 \\
\hline 9 & $\begin{array}{l}\text { No time baby } \\
\text { came suddenly }\end{array}$ & $36(10.0)$ & $8(1.4)$ & $<0.001$ \\
\hline 10 & $\begin{array}{l}\text { My culture } \\
\text { forbids }\end{array}$ & $5(1.4)$ & $0(0.0)$ & 0.009 \\
\hline 11 & No security & $2(0.6)$ & $1(0.2)$ & 0.564 \\
\hline 12 & Other (specify) ${ }^{\star}$ & $104(30.2)$ & $17(3.1)$ & $<0.001$ \\
\hline
\end{tabular}

${ }^{*}$ Other at endline includes preference for private hospital or home delivery, no money, not sick. Other at baseline includes no PHC facility, choice, had complications, dislike PHC, referred from PHC, among others. Non-response is excluded.

PHC, primary healthcare centre.

to be impactful if they are community driven and based on specific recommendations made by the immediate community. ${ }^{31}$ Such approaches recognise the wisdom of community women and elders and enlist their full participation to increase project support and effectiveness, strengthening its impact and sustainability over time. Combined interventions that bring together multiple approaches and partners are also more likely to be effective than those based on single interventions. ${ }^{32-34}$

To the best of our knowledge, this is one of a few interventions in sub-Saharan Africa that address the utilisation of PHC services in rural communities for skilled pregnancy. Some of the intervention activities were particularly novel and helped to accentuate the effectiveness of the interventions. These included the engagement of taxi drivers with rapid SMS that linked drivers with pregnant women and the PHCs and the development of community health insurance. The successful use of rapid SMS to improve healthcare delivery has been reported in some African countries. ${ }^{35} 36$ In Nigeria, it has been used for birth registration reporting, ${ }^{37}$ but not for maternal and child healthcare delivery.

The community health insurance helped to solve the problem of out-of-pocket financing in PHCs, which was identified by women as a barrier in accessing maternal 
healthcare. Although health insurance has been found to increase health facility utilisation, ${ }^{38-40}$ community health insurance, as used in this intervention, has not been found to be generally effective and sustainable in many parts of the world. ${ }^{41-43}$ However, the fact that this was cofunded by donations from community members and was handled by representatives of the communities with financial reporting done according to community mechanisms and norms may have increased the value of this aspect of the intervention.

In this study, we investigated whether there were differences in the reasons given by women for use or non-use of PHCs before and after the intervention. This was to enable us to determine any residual areas of concern initially raised by the women that need to be further addressed. The results showed that the cost of services was important to women in their decision to use and not use PHC services. While some reported that the costs are not too high, a few reported that the high cost of services was responsible for their continued non-use of PHC services after the intervention. For rural communities where the level of poverty is high, it is to be expected that out-ofpocket payments for healthcare and even health insurance contributions will have limited effects in generating demand for maternal health services. It is evident from the results of this study that health insurance or community funding of PHCs will not be adequate to bring all rural women to skilled pregnancy care. We believe that policies on active public funding of maternal health services that has featured as one of the components of universal health coverage, ${ }^{44-46}$ and which resulted in several governments offering free maternal and child health services in Nigeria, ${ }^{47-49}$ should be reconsidered as an essential element in ensuring the use of PHCs by women for skilled pregnancy care. ${ }^{50}$

Perceptions about the quality of skilled pregnancy care in PHCs also rated highly as remedial concerns by women even after the interventions. Although some respondents reported perceptions about low quality care as reasons for the non-use of PHCs after the intervention, some others reported that facilities now open regularly, that providers were more readily available, and that PHC services are of better quality after the intervention. These results indicate that although perceptions about the quality of services may have improved, there is a continuing need to intensify efforts in addressing the quality gaps associated with service delivery in the PHCs. The more educated women in the rural communities were still less likely to use the PHCs for maternal care (preferring the secondary, tertiary and private hospitals), indicating that more action is required to restore the confidence of all classes of people in the community in the services offered in PHCs aside from immunisation.

Another barrier identified before and after the intervention was gender inequality and cultural barriers. Although none of the women reported cultural barriers after the intervention, a substantial number mentioned 'husbands did not allow' as reasons for the non-use of
PHCs after the intervention. This indicates that although we applied gender transformative approaches during the study, including community conversations and interrogation with men and husbands, and dissemination of informational materials which focused on promoting gender inclusiveness in decision-making, there is still much more to be achieved in addressing gender inequality as an essential element in promoting the use of PHCs for skilled pregnancy care in the communities. Clearly, gender inequality is an important bottleneck to address in efforts to enhance women's use of skilled pregnancy care in the communities. ${ }^{1844}$

\section{Limitations}

The study was designed as a separate sample pretestposttest design. This design does not control possible threats to validity such as history and maturation, but with the use of a separate sample and the same questionnaire at the baseline and end survey, the design eliminates testing and instrumentation effect. Also, clustering and the personal characteristics of the respondents were adjusted in the statistical estimation. Furthermore, we are aware that during the 5 years duration of the project, no new interventions by government or related agencies related to the promotion of PHC usage or sexual and reproductive health and rights took place in the closely knit communities. There were no projects of a similar kind administered by civil society organisations or development partners in the area during the period. Thus, we are certain that the results obtained on PHC utilisation in this study are reflective of the activities of our intervention and not necessarily due to the interplay of other activities.

Another limitation of this research is the inability to estimate the independent effect of each intervention activity. Further studies are recommended to estimate the real impact of similar interventions on the performance of the health system and the health of the populations in terms of quality-adjusted life years gained, disabilityadjusted life years averted and life-years gained.

Also, many of the respondents who did not use a PHC in the project communities for delivery care at baseline did not respond to the question on reasons for non-use. This limits the understanding of the reasons for non-use of the PHCs in the project communities at baseline using a household survey questionnaire. However, the baseline was multimethod research; reasons for the non-use of a PHC for delivery care were also elicited through focus group discussion, community conversation and in-depth interviews. ${ }^{10} 1719$

\section{Policy recommendations}

The study has several policy and programmatic implications. Although PHCs have been endorsed as the entry points into Nigeria's formal health system, not much has been achieved in ensuring the demand and use of PHCs for maternal and child care. The results of this study indicate that the provision of PHCs in rural communities is 
not sufficient. Governments and implementing agencies must also work with communities to ensure the use of PHCs. Community engagement as reported in this study can help to address the barriers that prevent women from using skilled pregnancy care and can assist in connecting pregnant women with PHC services. We recommend a gradual extension of this model for optimising primary healthcare to the entire country and other parts of subSaharan Africa where similar circumstances prevail using the scaling impact approach developed by the International Development Research Centre, Canada. ${ }^{51}$

Policymakers in Nigeria have identified the use of WDCs as a component of PHC delivery in rural communities. They act as agents of change, advocates and promoters of PHC in communities where they serve. In 2018, the National Primary Health Care Development Agency renamed the programme 'Community Health Influencers, Promoters, and Services Programme (CHIPS) ${ }^{52}$ The results of this study provide substantive evidence that WDCs or CHIPS or similar programmes aimed at mobilising and engaging communities are effective in increasing the demand for PHC services for skilled maternal and child healthcare by rural women.

\section{CONCLUSION}

We conclude that interventions that address the specific concerns of women and stakeholders about the bottlenecks associated with the use of PHCs are effective in increasing the demand for maternal and child health services and can result in decreased maternal and under-5 mortality rate in the country.

\section{Author affiliations}

${ }^{1}$ Women's Health and Action Research Centre, Benin City, Nigeria

${ }^{2}$ Centre of Excellence in Reproductive Health Innovation (CERHI), University of Benin, Benin City, Nigeria

${ }^{3}$ Department of Demography and Social Statistics, Federal University Oye-Ekiti, Oye-Ekiti, Nigeria

${ }^{4}$ School of International Development and Global Studies, University of Ottawa, Ottawa, Ontario, Canada

${ }^{5}$ The George Institute for Global Health, University of Oxford, Oxford, UK

${ }^{6}$ Federal Ministry of Health, Abuja, Nigeria

${ }^{7}$ West African Health Organisation, Bobo-Dioulasso, Burkina Faso

\section{Twitter Friday Okonofua @feokonofua}

Acknowledgements We thank Francis Igberaese, Seun Anjorin and Joab Oghene who coordinated data collection and Michael Alli, Mary-Jane Emiowele, Precious Ntulu, Best Ojemhen, Jessy Ezebuihe, Peace Oppogen, Progress Emoitlotoga, Abubakar Zuleya, Ogechukwu Onwuma, Abumere Beverly, Endurace Imhanobe, Idididi Jeffery, Odaze Daniel, Sarah Eilegbogun, Victor Agbormikhe and others who were data collectors in the two LGAs. We are also grateful to Evans Ejedenawe, Raphael Okpaire, Cynthia Okojie, Tayo Ozobo, Akingbe Aminat, Ebunu Fatimetu, who served as community focal persons in both LGAs. They were instrumental in helping the project teams to gain access to the project communities. We acknowledge the contributions of Joy Adeniran who facilitated the design of the RapidSMS and Blessing 0mo-0morodion for the follow-up on the implementation.

Contributors F0 conceptualised the study, developed the methodology and wrote sections of the paper. LFN contributed to methodology, supervised the data collection, analysed the data and wrote sections of the paper. SY contributed to conceptualisation and methodology. $\mathrm{BI}, \mathrm{OS}$ and CE facilitated data collection and organisation and contributed to the interpretation of the data. EAKJ and IS contributed to conceptualisation, methodology and interpretation of the data; WI contributed to conceptualisation, methodology, and data collection. All authors reviewed and contributed to the first draft of this paper and approved the final version of the paper. F0 is responsible for the overall content of the paper.

Funding This study was funded by the International Development Research Centre, Canada in partnership with the Global Affairs Canada and Canadian Institute for Health Research under the Innovating for Maternal and Child Health in Africa (IMCHA) project. Grant number 108041.

Disclaimer The content is solely the responsibility of the authors and does not necessarily represent the official views of the funding organisations. The funding organisations did not influence the conduct, analysis and reporting of the analysis.

Competing interests None declared.

Patient consent for publication Not applicable.

Ethics approval This study involves human participants and was approved by Name of Ethics Committee: National Health Research Ethics Committee (NHREC) of Nigeria. Ethics approval ID number: NHREC/01/01/2007-10/04/2017. Participants gave informed consent to participate in the study before taking part.

Provenance and peer review Not commissioned; externally peer reviewed.

Data availability statement Data are available in a public, open access repository. OpenICPSR https://doi.org/10.3886/E123302.

Supplemental material This content has been supplied by the author(s). It has not been vetted by BMJ Publishing Group Limited (BMJ) and may not have been peer-reviewed. Any opinions or recommendations discussed are solely those of the author(s) and are not endorsed by BMJ. BMJ disclaims all liability and responsibility arising from any reliance placed on the content. Where the content includes any translated material, BMJ does not warrant the accuracy and reliability of the translations (including but not limited to local regulations, clinical guidelines, terminology, drug names and drug dosages), and is not responsible for any error and/or omissions arising from translation and adaptation or otherwise.

Open access This is an open access article distributed in accordance with the Creative Commons Attribution Non Commercial (CC BY-NC 4.0) license, which permits others to distribute, remix, adapt, build upon this work non-commercially, and license their derivative works on different terms, provided the original work is properly cited, appropriate credit is given, any changes made indicated, and the use is non-commercial. See: http://creativecommons.org/licenses/by-nc/4.0/.

ORCID iDs

Lorretta Favour Ntoimo http://orcid.org/0000-0002-3218-5535

Ermel Ameswue Kpogbe Johnson http://orcid.org/0000-0003-3663-5174

\section{REFERENCES}

1 United Nations. The millennium development goals report 2015. New York: United Nations, 2015.

2 United Nations General Assembly. Transforming our world: the 2030 agenda for sustainable development, 2015.

3 Butler J, Erken A, Hurskin I. Accelerating the promise: report on the Nairobi Summit on ICPD25. New York: United Nations Population Fund, 2019.

4 World Health Organization. Trends in maternal mortality: 1990 to 2015. estimates by WHO, UNICEF, UNFPA, the World Bank and the United nations population division. Geneva, Switzerland: World Health Organization, 2015.

5 The United Nations Inter-agency Group for Child Mortality Estimation (UN IGME).. Levels \& Trends in Child Mortality. New York, USA: UNICEF, 2020.

6 Adebowale S, Fagbamigbe F, Bamgboye E. Rural-urban differential in maternal mortality estimate in Nigeria, sub-Saharan Africa. Journal of Medical and Applied Biosciences 2010;2:74-91.

7 Adeyanju O, Tubeuf S, Ensor T. Socio-economic inequalities in access to maternal and child healthcare in Nigeria: changes over time and decomposition analysis. Health Policy Plan 2017;32:1111-8.

8 Okoli C, Hajizadeh M, Rahman MM, et al. Geographical and socioeconomic inequalities in the utilization of maternal healthcare services in Nigeria: 2003-2017. BMC Health Serv Res 2020;20:849.

9 Azuh DE, Azuh AE, Iweala EJ, et al. Factors influencing maternal mortality among rural communities in southwestern Nigeria. Int $J$ Womens Health 2017:9:179-88.

10 Ntoimo LFC, Okonofua FE, Igboin B, et al. Why rural women do not use primary health centres for pregnancy care: evidence from a qualitative study in Nigeria. BMC Pregnancy Childbirth 2019;19:1-13. 
11 Federal Government of Nigeria. Integrating primary health care governance in Nigeria (PHC under one roof): implementation manual. National Health Care Development Agency, 2013.

12 National Primary Health Care Development Agency (NPHCDA). Institutionalization of the primary health care planning and reviews in Nigeria: progress and status. Abuja, Nigeria, 2013.

13 NPHCDA. National primary health care development agency: minimum standards for primary health care in Nigeria. Abuja, Nigeria: Department of Planning, Research and Statistics, National Primary Health Care Development Agency, 2012. www.nphcda.gov.ng

14 Egbewale B, Odu O. Perception and utilization of primary health care services in a semi-urban community in south-western Nigeria. Journal of Community Medicine and Primary Health Care 2013;24:11-20.

15 Katung PY. Socio-economic factors responsible for poor utilisation of the primary health care services in a rural community in Nigeria. Niger J Med 2001;10:28-9.

16 Okonofua F, Ntoimo L, Ogungbangbe J, et al. Predictors of women's utilization of primary health care for skilled pregnancy care in rural Nigeria. BMC Pregnancy Childbirth 2018;18:106.

17 Fantaye AW, Okonofua F, Ntoimo L, et al. A qualitative study of community elders' perceptions about the underutilization of formal maternal care and maternal death in rural Nigeria. Reprod Health 2019;16:164.

18 Yaya S, Okonofua F, Ntoimo L, et al. Gender inequity as a barrier to women's access to skilled pregnancy care in rural Nigeria: a qualitative study. Int Health 2019;11:551-60.

19 Yaya S, Okonofua F, Ntoimo L, et al. Men's perception of barriers to women's use and access of skilled pregnancy care in rural Nigeria: a qualitative study. Reprod Health 2019;16:86.

20 Central Office of Research and. Edo state statistical Yearbook (20142020). Available: http://mda.edostate.gov.ng/budget/edo-statestatistical-yearbook-2014-2020/

21 Federal Ministry of Health. National health policy 2016: promoting the health of Nigerians to accelerate socio-economic development 2016.

22 Federal Ministry of Health. Nigeria health facility registry, 2021. Available: https://hfr.health.gov.ng/statistics/tables

23 Federal Government of Nigeria. Second national strategic health development plan 2018-2022, 2018.

24 Azuh DE. The role and challenges of ward development committees in promoting Grassroots health awareness in Ogun state Nigeria. Journal of Business and Management 2017;19:41-8.

25 National Primary Health Care Development Agency. National guidelines for the development of primary health care system in Nigeria. Fourth revised ed. Abuja, Nigeria: National Primary Health Care Development Agency, Federal Republic of Nigeria, 2012.

26 Aliyu AA, Dahiru T. Predictors of delayed antenatal care (Anc) visits in Nigeria: secondary analysis of 2013 Nigeria demographic and health survey (NDHS). Pan Afr Med J 2017;26:124.

27 Andersen R, Newman JF. Societal and individual determinants of medical care utilization in the United States. The Milbank Quarterly 2005;83:1-28.

28 Babalola S, Fatusi A. Determinants of use of maternal health services in Nigeria--looking beyond individual and household factors. BMC Pregnancy Childbirth 2009;9:43.

29 Kasso T, Chibianotu O, Ogu R. Determinants of disparity between antenatal Bookings and institutional deliveries in Port Harcourt, southern Nigeria. J Adv Med Med Res 2020:21-30.

30 Ononokpono DN, Odimegwu CO. Determinants of maternal health care utilization in Nigeria: a multilevel approach. Pan Afr Med J 2014;17(Suppl 1):2.

31 World Health Organization. Health systems in Africa community perceptions and perspectives. Brazaville, Republic of Congo: WHO Regional Office for Africa, 2012.

32 Brazier E, Andrzejewski C, Perkins ME, et al. Improving poor women's access to maternity care: findings from a primary care intervention in Burkina Faso. Soc Sci Med 2009;69:682-90.
33 Ordinioha B, Seiyefa B. Improving skilled attendants at birth: experience in a primary health care facility in rivers state, SouthSouth Nigeria. Journal of Community Medicine and Primary Health Care 2013;25:59-66.

34 Pence BW, Nyarko P, Phillips JF. The effect of community nurses and health volunteers on child mortality: the Navrongo community health and family planning project. New York, USA: Population Council, 2005.

35 Asiimwe C, Gelvin D, Lee E, et al. Use of an innovative, affordable, and open-source short message service-based tool to monitor malaria in remote areas of Uganda. Am J Trop Med Hyg 2011;85:26-33.

36 Ngabo F, Nguimfack J, Nwaigwe F, et al. Designing and implementing an innovative SMS-based alert system (RapidSMS-MCH) to monitor pregnancy and reduce maternal and child deaths in Rwanda. Pan Afr Med J 2012;13:31.

37 UNICEF. Nigeria-Using RapidSMS for birth registration, 2012. Available: https:blogs.unicef.org/innovation/Nigeria-using-rapidsmsfor -birth-registration

38 Browne JL, Kayode GA, Arhinful D, et al. Health insurance determines antenatal, delivery and postnatal care utilisation: evidence from the Ghana demographic and health surveillance data. BMJ Open 2016;6:e008175.

39 Gomez GB, Foster N, Brals D, et al. Improving maternal care through a State-Wide health insurance program: a cost and costeffectiveness study in rural Nigeria. PLoS One 2015;10:e0139048.

40 Hendriks ME, Wit FWNM, Akande TM, et al. Effect of health insurance and facility quality improvement on blood pressure in adults with hypertension in Nigeria: a population-based study. JAMA Intern Med 2014;174:555-63.

41 De Allegri M, Sauerborn R, Kouyaté B, et al. Community health insurance in sub-Saharan Africa: what operational difficulties hamper its successful development? Trop Med Int Health 2009;14:586-96.

42 Hounton S, Byass P, Kouyate B. Assessing effectiveness of a community based health insurance in rural Burkina Faso. BMC Health Serv Res 2012;12:363.

43 Soors W, Devadasan N, Durairaj V. Community health insurance and universal coverage: multiple paths, many rivers to cross. World Health Organization, 2010.

44 Rodin J. Accelerating action towards universal health coverage by applying a gender lens. Bull World Health Organ 2013;91:710-1.

45 World Health Organization. Making fair choices on the path to universal health coverage: final report of the who consultative group on equity and universal health coverage. Geneva, Switzerland: World Health Organization, 2014

46 World Health Organization. Public financing for health in Africa: from Abuja to the SDGs. World Health Organization, 2016.

47 Edu B, Agan TU, Monjok E, et al. Effect of free maternal health care program on Health-seeking behavior of women during pregnancy, intra-partum and postpartum periods in cross river state of Nigeria: a mixed method study. Open Access Maced J Med Sci 2017;5:370-82.

48 Mimiko O. Commentary: experiences with universal health coverage of maternal health care in Ondo state, Nigeria, 2009-2017. Afr J Reprod Health 2017;21:9-26.

49 Ogbuabor DC, Onwujekwe OE. Implementation of free maternal and child healthcare policies: assessment of influence of context and institutional capacity of health facilities in south-east Nigeria. Glob Health Action 2018;11:1535031.

50 Okonofua F, Lambo E, Okeibunor J, et al. Advocacy for free maternal and child health care in Nigeria-Results and outcomes. Health Policy 2011:99:131-8.

51 IDRC, Canada. Scaling impact: innovation for the public good. Available: https://www.idrc.ca/en/book/scaling-impact-innovationpublic-good [Accessed 17 Nov 2020].

52 National Primary Health Care Development Agency. Community health Influencers, promoters, and services programme. Available: nphcda.gov.ng/special programme [Accessed 4 Oct 2020]. 